\title{
OS IMPACTOS DA LEI N. 12.973/2014 EM UM ESCRITÓRIO DE CONTABILIDADE
}

Murillo José Torelli Pinto

Professor de Ciências Contábeis da Universidade Presbiteriana Mackenzie (UPM).

E-mail: murillo.torelli@mackenzie.br

Gabriela Augusto Russo

Graduada em Ciências Contábeis pela Universidade Presbiteriana Mackenzie (UPM).

E-mail: gabirussol@gmail.com

\section{Juliana Martinez Oliveira}

Graduada em Ciências Contábeis pela Universidade Presbiteriana Mackenzie (UPM).

E-mail: julimartinez@uol.com.br

\section{Lucas Magno de Moura Costa}

Graduado em Ciências Contábeis pela Universidade Presbiteriana Mackenzie (UPM). 


\section{RESUMO}

$\mathrm{O}$ artigo trata dos impactos decorrentes das alterações trazidas pela Lei n. 12.973/2014 para um escritório de contabilidade, tomando como ponto de vista os custos e desafios incorridos para o escritório com o início da vigência da lei. Foi realizada uma entrevista semiestruturada com o fundador de um escritório de contabilidade que existe há 40 anos que vivenciou de perto todas as mudanças que essa lei trouxe para o seu escritório. Além dessa entrevista, analisaram-se os dados da empresa, como os custos com empregados antes da lei e depois dela, demonstrando os impactos financeiros para o escritório. Ademais, visando corroborar as análises anteriormente citadas, efetuou-se uma entrevista com o sócio de outro escritório contábil com mais de 27 anos de atuação.

\section{PALAVRAS-CHAVE}

Lei n. 12.973. IFRS. Rotinas contábeis.

\section{INTRODUÇÃO}

A Lei n. 12.973/2014, fruto da Medida Provisória n. 627, tem como objetivo fazer a relação de entre a contabilidade societária nos padrões internacionais (International Financial Reporting Standards - IFRS) e a contabilidade fiscal que apura os tributos sobre o lucro, indicando os ajustes para neutralidade tributária dos efeitos IFRS. Essa neutralidade destina-se ao Fisco e aos contribuintes: a utilização dos pronunciamentos IFRS não deve nem aumentar, nem diminuir a carga tributária.

A adoção das IFRS no Brasil foi realizada em duas etapas. A primeira consistiu em adaptar a lei societária brasileira, representada pela Lei n. 6.404/76, aos padrões internacionais. Tais alterações foram feitas pela Lei n. 11.638/2007. A segunda etapa deu-se por meio da Lei n. 11.941/2009, que foi inicialmente concebida como medida provisória e posteriormente convertida em lei. Diante desse cenário, uma percepção de insegurança existiu entre os contribuintes brasileiros, pois não se conheciam ao certo os impactos tributários dessa mudança que era, a princípio, “apenas” societária.

O governo federal, visando adequar a lei tributária às mudanças societárias, 
sancionou a Medida Provisória n. 449 que, posteriormente convertida na Lei n. 11.941/2009, instituía o Regime Tributário de Transição (RTT), que durou até 2014 com a emissão da Lei n. 12.973/2014.

No entanto, como era de se esperar de uma lei complexa cujo propósito era regular, padronizar e alinhar as leis societária e tributária, a interpretação da Lei n. 12.973/2014 gerou uma incerteza quanto às suas mudanças. Visando solucionar esse problema, a Receita Federal emitiu a Instrução Normativa n. 1.515 e, posteriormente, a Instrução Normativa n. 1.700.

Este trabalho foi realizado com objetivo de responder à seguinte questão de pesquisa:

- Quais foram os impactos processuais para os profissionais e escritórios terceirizados da contabilidade com o início da vigência da Lei n. 12.973/2014?

O propósito do trabalho foi demonstrar os impactos financeiros causados pela Lei n. 12.973/2014 relacionados às mudanças na rotina dos serviços prestados pelos contadores e escritórios terceirizados de contabilidade e as dificuldades e os desafios que esses profissionais enfrentaram.

Justifica-se esta pesquisa ao trazer os impactos financeiros da Lei n. 12.973/2014 pelo ponto de vista do profissional contábil, ou seja, demonstrar como a adoção e implementação dessa lei impactou os processos e a rotina em um escritório de contabilidade, quais foram os incrementos e novos custos e despesas para o escritório, e como foi possível repassá-los aos clientes.

Por meio de entrevistas e pelo acesso a dados de um escritório de contabilidade, conseguiu-se obter resultados e responder ao problema de pesquisa. Ficou claro que essa lei mudou a rotina do escritório e trouxe impactos para toda a sociedade, fazendo com que todos sejam mais profissionais, além de introduzir ainda mais a tecnologia na rotina dos escritórios contábeis.

\section{REFERENCIAL TEÓRICO}

\section{Origem da lei}

De acordo com Almeida e Almeida (2015), a globalização é o ponto de partida de todas as leis/normas e outras ações tomadas que visam a uma maior harmonização das normas contábeis, fazendo com que transações similares recebam tratamentos similares e tenham impactos semelhantes 
nas contas patrimoniais e no resultado de qualquer entidade, independentemente dos países em que estejam localizadas as empresas. As práticas contábeis adotadas mundialmente visando a essa harmonização são as IFRS emitidas pelo International Accounting Standards Board (Iasb), de modo a facilitar a compreensão e análise de dados financeiros por parte dos usuários da contabilidade.

A implementação das IFRS no Brasil, como bem descrito por Almeida e Almeida (2015), ocorreu em duas etapas, em 2008 e em 2010. Na primeira etapa, o governo federal sancionou a Lei n. 11.638/2007 e, na segunda, a Medida Provisória n. 449 (convertida na Lei n. 11.941/2009) que promovia diversas mudanças na lei societária brasileira (Lei n. 6.404/76). Diante desse cenário que causou insegurança nos contribuintes quanto aos impactos tributários dessas mudanças na legislação, a Medida Provisória n. 449 instituiu o RTT. O RTT foi estabelecido com a finalidade de "neutralizar" de maneira temporária os efeitos tributários decorrentes dessa adoção das IFRS no Brasil, sendo opcional nos anos de 2008 e 2009 e tornando-se obrigatório somente no ano de 2010, alterando as apurações de Imposto de Renda de Pessoa Jurí- dica (IRPJ), Contribuição Social sobre Lucro Líquido (CSLL), Programa de Integração Social (PI)S e Contribuição para Financiamento da Seguridade Social (Cofins). Posteriormente, visando regulamentar de forma definitiva os efeitos fiscais da adoção das IFRS, o governo federal publicou a Medida Provisória n. 627/2013, convertida posteriormente na Lei $n$. 12.973/2014, que também revogava o RTT, eliminando, assim, os ajustes de práticas contábeis.

A Figura 1 representa o modo de apuração do lucro real em meio a essas leis.

Nos tópicos seguintes, serão apresentadas duas mudanças pontuais da lei que causaram impactos no trabalho dos profissionais da contabilidade.

\section{Regime Tributário de Transição (RTT)}

O RTT foi instituído a partir de 2008. Trata-se dos ajustes tributários decorrentes dos novos métodos e critérios contábeis introduzidos pela Lei n. 11.638/2007 e pelos artigos 36 e 37 da Medida Provisória n. 449/2008, convertidos nos artigos 37 e 38 da Lei n. 11.941/2009. O RTT chega ao fim com a entrada em vigor da lei que disciplina os efeitos tributários dos 
MÉTODOS DE APURAÇÃO DE IRPJ E CSLL

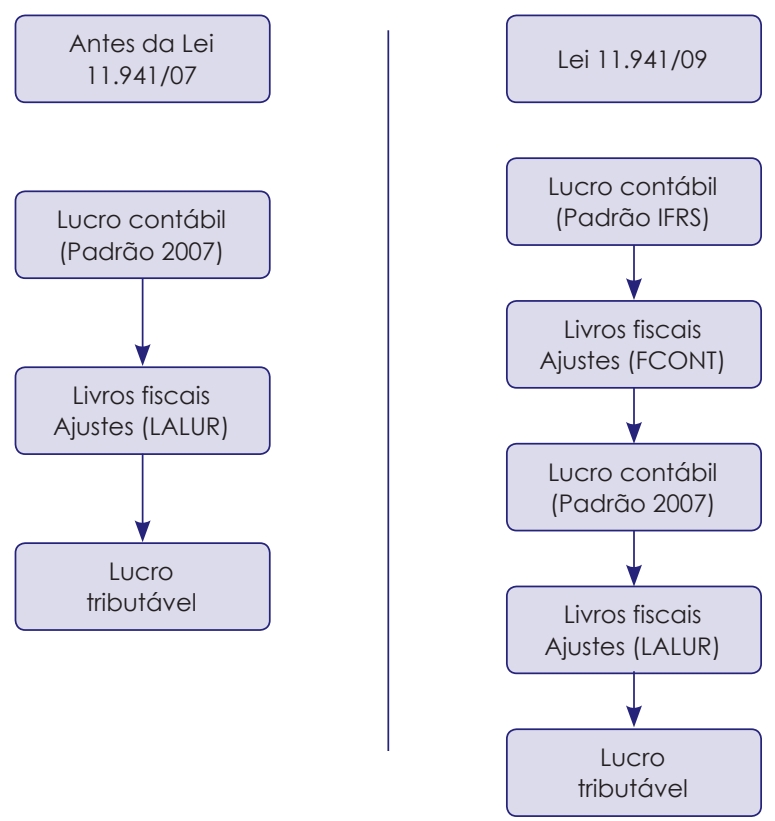

Lei $12.973 / 14$

Lucro contábil (Padrão IFRS)

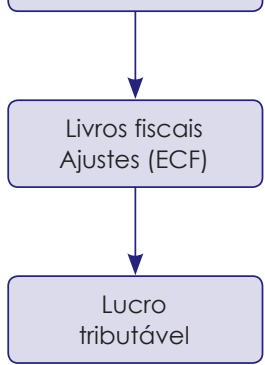

FIgURA 1 - Comparação do antes e depois com RTT Fonte: Elaborada pelos autores.

novos métodos e critérios contábeis, buscando a neutralidade tributária, no caso, a Lei n. 12.973/20414 (Instrução Normativa da Receita Federal do Brasil (RFB) n. 949/2009).

\section{Sistema Público de Escrituração Digital (SPED)}

Outra obrigatoriedade imposta pela Lei n. $12.973 / 14$ foi a entrega do novo arquivo de SPED. A escrituração contábil e fiscal de pessoas jurídicas, que anteriormente era efetuada por meio da obrigação acessória muitas vezes em papéis, passou a ser exigida em um novo modelo digital e mais complexo. Trata-se da Escrituração Contábil Fiscal (ECF).

Como a partir de 2014 as empresas passam a ser obrigadas a ter a contabilidade societária e também a contabilidade fiscal, a Receita Federal manteve a Escrituração Contábil Digital (ECD) com dados societários e criou a ECF com dados fis- 
cais. A ECD substitui a impressão de diversos livros que antigamente eram feitos em papel, como o livro diário, livro-razão, balancetes e balanços. Assim também surgiu a ECF, a qual substituiu a Declaração de Informações Econômico-Fiscais da Pessoa Jurídica (DIPJ). Contendo um volume significativo de informações quando comparada à DIPJ, a ECF levou as empresas a informar obrigatoriamente todas as operações que influenciam a composição da base de cálculo e o valor devido do IRPJ e da CSLL.

A ECF foi implantada pela RFB, por meio da Instrução Normativa n. 1.422/2013 (alterada posteriormente pela Instrução Normativa n. 1.489/2014). Ao contrário das poucas fichas da DIPJ, na ECF é uma obrigação acessória muito mais extensa. Há também a inclusão dos Livros de Apuração do Lucro Real (Lalur) e da Contribuição Social (Lacs).

Com tais mudanças, as organizações contábeis, a fim de escriturarem corretamente os novos livros, passam a investir em gestão contábil, controles de registros e treinamento de seus colaboradores. Além disso, há a necessidade de repassar esses custos incrementais aos honorários cobrados de seus clientes para que todas as informações cheguem com fidedignidade e em tempo hábil para conclusão do trabalho.

Dentro da ECF consta o e-Lalur - antigamente o Lalur era feito em papel e agora será emitido com os registros contábeis auxiliares que passam a ser entregues via SPED. Vale destacar que esse livro somente era apresentado para o órgão fiscalizador quando solicitado em uma fiscalização presencial. Atualmente, com o e-Lalur na ECF, a apresentação do livro é espontânea e obrigatória de maneira digital.

\section{PROCEDIMENTOS METODOLÓGICOS}

O foco deste trabalho foi apurar e demonstrar os efeitos que a Lei n. 12.973/2014 teve na rotina e nos custos de um escritório de contabilidade. Para atingir tal objetivo, nossa pesquisa teve como amostra uma empresa prestadora de serviços de contabilidade, localizada em Guarulhos, na Grande São Paulo, em sede própria, uma empresa com mais de 40 anos de história e tradição, com foco em servir, ser útil e, primordialmente, prestar um bom serviço que deixe seus clientes felizes e satisfeitos. 
A empresa em questão tem atualmente mais de 50 colaboradores em diversos departamentos, como recursos humanos, fiscal, contábil e regularização. Conta também com mais de 400 clientes na sua carteira, e aproximadamente metade deles estão enquadrados nos regimes tributários de lucro real ou lucro presumido, envolvidos nas mudanças da Lei n. $12.973 / 2014$.

A pesquisa, por ser baseada em entrevistas e análises de dados, é caracterizada como uma pesquisa qualitativa exploratória. De acordo com Godoy (1995), em pesquisas qualitativas, não se procura enumerar ou medir os eventos estudados, nem se utilizam ferramentas estatísticas no tratamento dos dados coletados. Esse tipo de pesquisa se preocupa com a obtenção de dados descritivos sobre determinados fatores, como pessoas e lugares. Segundo Godoy (1995), a pesquisa qualitativa tem o ambiente natural como fonte direta de dados e tem na figura do pesquisador um instrumento fundamental.

Para descrever uma pesquisa exploratória, Gil (2008) afirma que ela tem como principal finalidade esclarecer algum conceito, evidenciando uma visão ampla sobre determinado assunto. Geral- mente, envolve levantamento bibliográfico e estudos de caso, além de entrevistas não padronizadas.

Para a coleta de dados, foram feitas duas entrevistas semiestruturadas com os sócios e fundadores dos escritórios de contabilidade que constituem nossa amostra, de forma a obter uma maior eficácia e credibilidade nos dados coletados.

Além da entrevista, teve-se acesso aos balancetes de 2012 até 2017, o que permitiu a análise desde um período anterior até um período posterior à Lei n. 12.973/2014, de modo a triangular as respostas encontradas na entrevista com os dados encontrados. Conforme acordado com o entrevistado, somente são apresentados os dados em percentuais. Ademais, foram feitas conversas informais com os funcionários dessa empresa, com o propósito de trazer para o presente trabalho a visão deles sobre o período de transição do SPED.

A entrevista realizada com o sócio e fundador da empresa ocorreu no dia 21 de agosto de 2018, das 15 às 16 horas, em sala reservada na sede da empresa, em Guarulhos, na Grande São Paulo.

Também se realizou outra entrevista com o sócio e contador de outro escritó- 
rio de contabilidade, situado no centro de São Paulo, com mais de 27 anos de atuação no mercado e que conta atualmente com um portfólio de aproximadamente 200 empresas, entre micro, pequenas e médias empresas, sendo grande parte de lucro presumido e algumas do lucro real. A entrevista ocorreu no dia 27 de setembro de 2018, das 12 às 12h30, a fim de corroborar nossa análise a partir da amostra.

\section{ANÁLISE DOS RESULTADOS}

Nos tópicos a seguir, descrevem-se as respostas obtidas na entrevista, uma análise dos percentuais obtidos a partir dos balancetes de antes, durante e depois da Lei n. $12.973 / 2014$ e as respostas obtidas com a segunda entrevista, realizada com o propósito de comparar com a análise dos dados obtidos a partir de nossa amostra.

\section{Entrevista}

$\mathrm{Na}$ primeira entrevista, obtiveram-se informações importantes de como a Lei n. 12.973/2014 impactou não somente a empresa do entrevistado, como também todo o setor de contabilidade. Entre suas respostas, ele afirmou: "este talvez foi o período de maior dificuldade para a empresa, desde a fundação".

Durante a entrevista, o fundador narrou que teve de realizar diversas ações visando adequar sua empresa à nova demanda de informações do Fisco. Mencionou que teve de aumentar o quadro de funcionários, contratar profissionais capacitados para essa demanda, investir em equipamentos mais novos e potentes e também em treinamento para seus empregados a fim de capacitá-los.

Nesta época de mudanças, muitos sistemas ERP, inclusive o seu, encontravam-se defasados e sem estrutura para realizar as novas funções que eram exigidas pelo Fisco. Por tal motivo, transferiu a execução do serviço fiscal e contábil de todas as empresas tributadas pelo lucro real ou presumido para as próprias empresas, contratando funcionários especificamente para fazer esse trabalho externamente. Além disso, ajudou seus clientes em contatos com diversas empresas de informática visando auxiliá-los a escolher um sistema ERP que lhes desse total suporte e apoio no dia a dia. Mais uma vez, prezando seus clientes, ele ofereceu treinamento a eles, por meio de seu consultor 
tributário e do especialista em tecnologia da informação (TI).

Vale ressaltar que, em contato com contadores de outras empresas, percebeu-se que esses gastos estavam sendo repassados aos clientes com valores em torno de 5 a 10 mil reais, enquanto sua contabilidade absorveu todos esses gastos, não repassando nenhum gasto para seus clientes fora a mensalidade com os honorários acordados previamente.
Em conversa com alguns funcionários dessa empresa, ficou claro que a transição para o SPED foi de certa forma traumática para todos, incluindo profissionais da área contábil e contribuintes, pois envolveu diversas mudanças, criação de regras e penalidades que trouxeram medo e um cenário de insegurança generalizado.

\section{Análise dos dados}

TABELA 1 - Contas do escritório 2012-2017

\begin{tabular}{lccc}
\hline Nome da conta & $\begin{array}{c}\text { Variação antes } \\
\text { e depois }\end{array}$ & $\begin{array}{c}\text { Variação durante } \\
\text { e depois }\end{array}$ & $\begin{array}{c}\text { Variação antes } \\
\text { e depois }\end{array}$ \\
\hline Equipamentos - máquinas e instalações & $86 \%$ & $9 \%$ & $103 \%$ \\
\hline Equipamentos de informática & $80 \%$ & $9 \%$ & $97 \%$ \\
\hline Móveis e utensílios & $27 \%$ & $37 \%$ & $74 \%$ \\
\hline Despesas operacionais & $7 \%$ & $9 \%$ & $17 \%$ \\
\hline Despesas administrativas & $16 \%$ & $20 \%$ & $19 \%$ \\
\hline Despesas com pessoal & $9 \%$ & $9 \%$ & $16 \%$ \\
\hline Salários e outros & $7 \%$ & $8 \%$ & $153 \%$ \\
\hline Alimentação do trabalhador & $137 \%$ & $7 \%$ & $-46 \%$ \\
\hline Ativo & $-6 \%$ & $-43 \%$ & $-8 \%$ \\
\hline Passivo & $83 \%$ & $-49 \%$ & $-2 \%$ \\
\hline Receita & $-6 \%$ & $4 \%$ & $16 \%$ \\
\hline Despesa & $-78 \%$ & $-22 \%$ & $-83 \%$ \\
\hline Lucro & $11 \%$ & $9 \%$ & $19 \%$ \\
\hline
\end{tabular}

Fonte: Elaborada pelos autores. 
Teve-se acesso aos balancetes da empresa de 2012 a 2017, e alguns pontos se destacam e corroboram a fala do empresário. Ele disse que teve de fazer muitos investimentos em equipamentos mais atualizados para conseguir permanecer atualizado perante o Fisco e efetuar corretamente a entrega das obrigações, e, em seus dados, percebe-se um aumento do valor de equipamentos de informática declarado de 2012 a 2017, ou seja, desde antes e até depois da lei, de 97\%. Esse dado fica mais evidenciado ainda porque esse valor aumentou somente 9\% de 2014 a 2017, ou seja, fica muito claro que o período em que ocorreram esses investimentos coincide com a época em que a Lei n. 12.973 entrou em vigor.

No entanto, outro ponto que sofreu uma majoração relevante e não foi mencionado pelo entrevistado refere-se a móveis e utensílios, com um aumento de $74 \%$ entre o período antes e depois da referida lei. Tal efeito pode ter passado despercebido por diversos fatores, como mudanças relacionadas a melhoras já programadas por ele ou mudanças inesperadas, mas não se devem descartar os efeitos da lei, pois, ao adquirir novos equipamentos e contratar novos funcionários, provavelmente ti- veram de ser feitas mudanças estruturais e de ocupação de espaço, ou seja, seria um efeito indireto da lei.

Com relação às despesas, podem-se citar as administrativas, que sofreram um aumento de $40 \%$ no período pré e pós-lei. Pode-se afirmar que essa majoração nas despesas administrativas foi decorrente do aumento de materiais de escritório, além de contas como energia elétrica, água e telefone, pois o escritório trabalhou por mais horas para a entrega das obrigações no prazo estabelecido.

Confrontando com os dados, a menção do dono da empresa com relação às despesas com pessoal e empregados pode ser identificada por meio do aumento razoável de 19\%, de 2012 a 2017, que provavelmente se deve à contratação de profissionais mais preparados, além do investimento em capacitação de todos os seus funcionários.

A contratação de mais empregados incorreu em mais gastos com benefícios, principalmente alimentação, a qual obteve um aumento significativo de 153\% desde antes e até depois da implementação da lei, sendo $137 \%$ durante o processo de implementação dela, ou seja, de 2012 a 2015, provavelmente por causa da necessidade 
de proporcionar maiores benefícios aos seus funcionários, visando contratar profissionais mais competentes e que são mais concorridos entre as empresas. Esse aumento muito significativo também se deve às mudanças nas leis trabalhistas que geraram novos gastos às empresas.

Quando se analisam os dados da empresa entre ativos e passivos totais no período antes e depois da lei, percebe-se um grande declínio no valor do ativo total da empresa, enquanto o passivo sofreu uma leve queda. $\mathrm{O}$ ativo da empresa diminuiu $46 \%$ entre antes e depois da lei, um indicativo de que a empresa realmente passou por um período muito difícil e ainda está tentando retomar seu nível pré-2014. O passivo aumentou $83 \%$ entre 2012 e 2015, no entanto caiu 50\% de 2015 até hoje, fazendo com que seu saldo no período tenha sido uma pequena queda de $8 \%$, algo muito longe do grande declínio que o ativo apresentou. Essa redução quase que exclusiva do ativo, sem efeitos no passivo, tem efeito em patrimônio líquido menor, mostrando que o período de implantação da lei gerou uma redução de riqueza para os sócios do escritório contábil.

Adicionalmente, teve-se acesso aos dados de receitas, despesas e lucro final da empresa, e, corroborando os demais dados já apresentados, percebe-se que o lucro da empresa foi afetado de 2012 até hoje, sofrendo uma queda de $83 \%$, alavancada pela queda de $78 \%$ entre 2012 e 2015 , desde antes até o momento de implementação da lei. Nesse período, as receitas permaneceram praticamente constantes, enquanto as despesas aumentaram 16\%, resultando na grande queda do lucro da empresa.

\section{Entrevista comparativa}

Essa segunda entrevista trouxe aspectos muito interessantes e ratificou alguns pontos tratados e abordados no trabalho, de acordo com a nossa amostra. Durante a entrevista, ficou claro que as obrigações trouxeram um impacto na rotina do escritório. Ao tratar do preenchimento da ECF, o entrevistado disse ser muito mais complexo que o da DIPJ, o que acarretou a necessidade de revisar alguns lançamentos contábeis, a parametrização do plano de contas com o padrão SPED, entre outros procedimentos.

$\mathrm{O}$ entrevistado mencionou ainda que esta década tem sido diferenciada, principalmente por causa das Leis $n^{\circ}$ S 11.638/2007 e 12.973/2014. Além disso, disse que, para 
atender ao controle do Fisco, houve acúmulo de trabalho, o que gerou a necessidade constante de aprimoramento do profissional contábil. Para isso, foram realizados diversos treinamentos internamente a fim de melhorar o conhecimento dos colaboradores e instituir parâmetros para a elaboração e entrega dessa nova declaração. E também se tornou essencial e fundamental a constante atualização de máquinas, sistemas, hardwares e softwares.

Com isso, ele encerra afirmando que os maiores custos estão relacionados com o investimento em mão de obra especializada e treinamento, além do investimento em equipamentos e os gastos com sua respectiva manutenção. Mencionou ainda que esses custos foram parcialmente repassados aos seus clientes por meio da cobrança pela entrega das declarações da ECD e ECF.

\section{CONSIDERAÇÕES FINAIS}

O desenvolvimento deste trabalho cujo propósito foi demonstrar os efeitos da adoção da Lei n. 12.973/2014 nos processos e na rotina dos escritórios de contabilidade possibilitou concluir que ela realmente trouxe impactos relevantes para os escritórios contábeis, principalmente nos recursos de mão de obra qualificada e TI.

E para se chegar a essa conclusão, foram definidos dois procedimentos. Primeiramente, entrevistaram-se os sócios dos escritórios, que foram essenciais na busca para o trabalho, haja vista que era necessário ouvir as pessoas e mostrar o ponto de vista delas. Assim sendo, tentou-se traduzir o mais fielmente possível as falas e reações dos entrevistados. Depois, para demonstrar fidedignamente os impactos, analisaram-se, de forma complementar, as contas dos balancetes de um desses escritórios, em que se utilizaram os dados de 2012 a 2017, de modo a retratar todo o período em questão, antes, durante e após a lei.

$\mathrm{O}$ primeiro entrevistado disse que incorreu em diversos custos, como treinamento de funcionários, compra de novos equipamentos mais potentes que conseguissem atender à nova demanda de informações, além de aumento do quadro de empregados, contratando profissionais capacitados. Também auxiliou seus clientes em contatos com diversas empresas de informática, visando à escolha de um sistema ERP que lhes desse total suporte e apoio no dia a dia. Além disso, proporcionou treinamentos para que os funcioná- 
rios entendessem como a nova lei impactaria as empresas.

Quando se analisaram os dados da empresa gerida pelo primeiro entrevistado, percebeu-se que os gastos incorridos em contratação e aperfeiçoamento dos empregados e aquisição de novos equipamentos impactaram efetivamente o resultado da empresa por conta do aumento demasiado, o que, por consequência, resultou no aumento das despesas totais da empresa no período pós-lei. Por causa também da lei e do momento financeiro instável do país como um todo, o lucro da empresa diminuiu, o que gerou mais dificuldades e desafios ao entrevistado.

Já o segundo entrevistado afirmou que esta década tem sido diferenciada pela quantidade de novas leis e pelas mais diversas mudanças que elas trouxeram para o profissional contábil. Também, ratificando a primeira entrevista, disse que seus gastos com mão de obra especializada e novos equipamentos foram os maiores gastos efetuados por ele no período.

Com isso, pode-se dizer que o maior impacto foi em relação à entrega das obrigações, à dificuldade de entender a complexidade desse sistema e se adaptar a ele. Percebe-se também que as mudanças des- critas na metodologia realmente se confirmaram, haja vista as entrevistas concedidas e analisadas, além das mudanças em receitas, despesas e outras contas analisadas.

Essa lei implicou muitos gastos para todos os escritórios contábeis, independentemente do porte deles, em despesas operacionais e administrativas. Em razão do cenário socioeconômico da sociedade e da dúvida que pairava sobre todos a respeito da lei, muitos desses gastos foram absorvidos pelos escritórios, seja totalmente, como o escritório de nossa amostra, seja parcialmente, como relatado pelo dono do segundo escritório.

Conclui-se que essa lei onerou tanto os contabilistas como os contribuintes, trazendo um poder maior de fiscalização e controle do Fisco. A contratação de funcionários, o treinamento deles e a aquisição e manutenção de novos equipamentos foram efetivamente, segundo os dois entrevistados, os gastos que tiveram mais impacto.

\section{THE IMPACTS OF LAW N. 12.973/ 2014 ON AN ACCOUNTING FIRM}

\section{ABSTRACT}

The article deals with the impacts arising from the changes brought by Law n. $12.973 / 2014$ to an 
accounting office, taking as a point of view the costs and challenges incurred for the office with the beginning of the law. A semi-structured interview was held with the founder of an accounting firm that has existed for 40 years and has experienced intimately all the changes this law has brought to his office. In addition to this interview, we analyzed company data, such as costs before and after law employees, demonstrating the financial impact on the firm. Besides, to corroborate the analyzes as mentioned above, an interview was conducted with the partner of another accounting office with more than 27 years of operation.

\section{KEYWORDS}

Law n. 12.973. IFRS, Accounting routines.

\section{REFERÊNCIAS}

ALMEIDA, M. C.; ALMEIDA, R. J. Regulamentação fiscal das normas contábeis do IFRS e CPC. São Paulo: Atlas, 2015.

BRASIL. Lei n. 12.973, de 13 de maio de 2014. Disponível em: http://www.planalto.gov.br/ccivil_03/_ato2011-2014/2014/ lei/l12973.htm. Acesso em: 20 mar. 2018. DURÃES, A. N. A. Lei 12.973/2014 - IRPJ, PIS/PASEP, COFINS, RTT - Alterações. São Paulo: CRC, set. 2014. Disponível em: http://crc-es.org.br/wp-content/ uploads/2013/11/Lei-12.9732014\%E2\%80\%93-IRPJ-PISPASEP-COFINSRTT-\%E2\%80\%93-Altera\%C3\%A7\% C3\%B5es-\%E2\%80\%93-Prof.-Arn\%C3\% B3bio-Neto-Araujo-Dur\%C3\%A3es.pdf. Acesso em: 6 jun. 2019.

GIL, A. C. Métodos e técnicas de pesquisa social. 6. ed. São Paulo: Atlas, 2008.

GODOY, A. S. Introdução à pesquisa qualitativa e suas possibilidades. Revista de Administração de Empresas, São Paulo, v. 35, n. 2, p. 57-63, 1995.

GUERRA, F. Escrituração Fiscal Digital SPED ECF. Sergipe, 2015.

NEVES JÚNIOR, I. J. das; OLIVEIRA, C. M. de; CARNEIRO, E. E. Estudo exploratório sobre os benefícios e desafios da implantação e utilização do Sistema Público de Escrituração Digital - SPED na opinião de prestadores de serviços contábeis no Distrito Federal. In: CONGRESSO DA USP DE INICIAÇÃO CIENTÍFICA EM CONTABILIDADE, 8., 2011, São Paulo. São Paulo: USP, 2011.

PRODANOV, C. C.; FREITAS, E. C. de. Metodologia do trabalho científico: métodos e técnicas da pesquisa e do trabalho acadêmico. 2. ed. Novo Hamburgo: Feevale, 2013. 
MURILLO JOSÉ TORELLI PINTO, GABRIELA AUGUSTO RUSSO, JULIANA MARTINEZ OLIVEIRA, LUCAS MAGNO DE MOURA COSTA

REBELATTO, D. Projeto de investimento.

Barueri: Manole, 2004.

RODRIGUES, A. O. et al. Manual da ECF.

4. ed. São Paulo: IOB, 2019.

ZANELLA, L. C. H. Metodologia de pesquisa.

2. ed. Florianópolis: Editora da UFSC, 2011. 